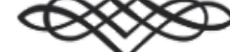

Reading in between the seams: the connection

between aesthetics and society in the XX century

\title{
Leer entre costuras: la conexión entre la estética y la sociedad en el siglo XX
}

Belén Fernández de Alarcón Roca

Universidad Rey Juan Carlos

belen.fernandezdealarcon@urjc.es

Marta Isabel GonzÁlez de la Rubia

Universidad Rey Juan Carlos

martagonzalezdelarubia95@gmail.com

DOI: https://doi.org/10.15366/bp.2020.24.021

Bajo Palabra. II Época. № 24. Pgs: 415-430 
Recibido: 18/05/2020

Aprobado: $12 / 08 / 2020$

Resumen

Este artículo pretende poner en relieve la importancia del estudio de la estética enfocado a la moda como portadora de un mensaje, además de mostrar cómo el estudio teórico y a nivel filosófico de la moda ha atraído la atención de diversos intelectuales desde el siglo XIX, tal como se muestra en la primera parte. En la segunda, se encuentran ejemplos para ilustrar los estudios teóricos, siendo los protagonistas el cambio constante, los diseñadores, y sus diseños, los portadores de un mensaje escondido "entre las telas y las costuras" donde se reflejaba la realidad en el momento de su creación, manifestando cómo en la forma de vestir se pueden leer movimientos culturales, políticos, económicos, o los cambios en la manera de pensar.

Palabras clave: Estética, Moda, Estilo, Alta Costura, Globalización, Democratización de la moda.

\section{Abstract}

This article aims to showcase the importance of the study of aesthetics, focusing primarily on fashion and the way of dressing as the carriers of a message, as well as displaying how theoretical and philosophical studies of fashion have caught the attention of a plethora of intellectuals from the XIX century, as the first part of this article focuses. The second part contains examples that illustrate the theoretical studies, in which constant changes, designers and most importantly, their designs, 'in-between fabrics and seams', carry hidden messages that reflect the reality of what was happening in a particular moment in time, like the cultural, political, and economic movements of the era that may also reflect changes in the way people think.

Keywords: Aesthetic, Fashion, Style, Haute Couture, Globalisation, Democratisation of Fashion. 


\section{Introducción}

LA ESTÉTICA ES EL ESTUdio DE LO BELlo, en toda su amplitud. Su estudio apareció en la Antigua Grecia, centrándose en el mundo de las ideas y conforme pasó el tiempo, fundamentalmente se centró en el estudio de la obra de arte, pero siempre dependiendo de las corrientes filosóficas que se desarrollaran en el momento. Asimismo nació y evolucionó como una reflexión del "ver", o de "cómo ver". Es la representación del momento y de lo que cambia, pero sobre todo es el estudio del saber mirar a través de los pequeños detalles. Siempre atada a la sensibilidad y al empirismo de manera más o menos individual, cada estudio o corriente estética buscaba estar un poco más cerca de la Verdad sobre como captar la realidad y manifestarla.

Fue en el siglo XIX el punto de inflexión en lo que respecta al objetivo de este artículo, cuando comenzaron a aparecer los primeros tratados de estética enfocados a la moda; hasta entonces, la estética se centraba más en el concepto general de la belleza o del gusto. La estética se centraba en el mundo de las ideas, por lo que estos primeros estudios trataron cómo la estética imbuye el sentido del gusto, transformándose en moda.

Saber leer la vestimenta de una época, o de determinados grupos de una sociedad, habla del momento que se está desarrollando. Cuando hay un gran cambio social, cuando un hecho importante cambia el camino de los acontecimientos o las costumbres sociales, así como a la vez varía la situación económica o política, lo primero que cambia son dos cosas: el arte y el modo en el vestir, y muchas veces lo hacen a la vez y otras, incluso preveen ese cambio que va a acontecerse debido a la aparición o desaparición de pequeños detalles en las vestimentas, lo cual está relacionado directamente con el gusto, que es una de las bases más importantes a la hora de estudiar la estética, ya que al cambiar la manera en el vestir, inevitablemente cambia el gusto de una sociedad completa y el significado de éste.

\section{Estudios sobre el concepto de la moda}

PARA ELLO, ES IMPORTANTE TENER EN CUENTA la evolución cronológica no solo del concepto "moda", sino también cuales han sido los cambios, sobre todo, a nivel 
estético y cómo ha estado unido constantemente el arte, la historia y las reflexiones sobre la sociedad de las diferentes épocas. La moda aparece en el momento en el que el arte presenta una tendencia hacia la exageración y el horror vacui: el siglo XVIII. ${ }^{1}$ Esto quiere decir que las personas se convirtieron en espejos de los cambios estéticos que acontecían en el mundo del arte, y la forma de vestir empieza a cambiar tan precipitadamente como suceden los hechos en los países y tan rápidamente como los artistas crean nuevas obras y descubren nuevos estilos.

Es fundamental además tener en cuenta que desde el siglo XVIII hasta principios del XX muchos diseñadores se consagraron (y fueron consagrados) como auténticos artistas, llevando a sus creaciones textiles no solo el mundo del arte, sino el concepto de belleza. Para que una moda se asiente en la sociedad y conseguir un cambio estético, lo creado debe ser bello, y para crear algo bello, la idea de lo bello y el estudio del gusto deben ser una reflexión previa al trabajo creativo. Sin embargo, el hecho de que durante este tiempo la moda se considerara un arte, abre la puerta a reflexionar sobre otra idea: ¿desapareció en cierto modo el concepto de lo sublime y la idea inalcanzable de la belleza cuando se sacralizó la moda llevando al día a día de las personas aquello que se suponía un ideal? ${ }^{2}$

La indumentaria siempre ha sido objeto de admiración y de crítica. Ha sido debate entre lo moralmente correcto y las normas estéticas, ya que salirse de la línea marcada por la moda imperante, siempre se ha considerado no solo extravagante, sino que también se ha identificado como una ofensa o un símbolo ideológico, desde los sans-culotte en la Revolución Francesa, hasta los uniformes militares, y esto porque la manera de vestir manda ese mensaje. Se le atribuyen unos símbolos que se acomodan en la conciencia colectiva y se los identifica e identificaba como conocidos o desconocidos, como extravagantes, como pasados de moda, como pertenecientes a una clase social o a otra, a un país o a otro, o incluso con un sentido ideológico.

Hay veces que la unión con la filosofía y sus máximos representantes se ha hecho tangible a nivel visual. María Antonieta (1755-1793) fue el gran referente de su época en cuanto a moda, llegando ésta a ser considerada un auténtico arte y llegando a convertirse su manera de vestir en asunto de Estado. ${ }^{3}$ La reina comenzó a leer a Rousseau, quien en sus escritos atacó la superficialidad de la moda y del Rococó, partiendo de la afirmación de Montesquieu de que los romanos desconocían el lujo; comenzó así a defender una vuelta a lo rural, al ascetismo, atacando al consumismo

\footnotetext{
Lipovetsky, C, El Imperio de lo efímero, Barcelona, Anagrama, 1996, p.69

Ibid, p.99

3 Cerrillo, L., La moda moderna. Génesis de un arte nuevo, Madrid, Ed. Siruela, 2010, p.27
} 
exacerbado que dejaba de lado las verdaderas preocupaciones y asuntos importantes de la sociedad. ${ }^{4}$

Así, resulta llamativo que una figura como María Antonieta, una de las máximas representantes del Antiguo Régimen y del lujo, fuera seguidora de Rousseau y adquiriera ciertos principios defendidos por él, aunque hay que destacar que adaptó estos principios a su situación. Esto significa que prácticamente se trasladó a vivir a Le Petit Trianón, un pequeño palacete situado dentro del área de Versalles en el que la reina quiso llevar una vida más rural y natural, instalando allí un huerto y una granja. Comenzó a vestir sin corsé, con vestidos de muselina blanca llamados en la corte chemise de la reine y sombreros de paja. Esto suscitó grandes críticas en la corte y los círculos oficiales hasta el punto de ser acusada de que su nueva imagen no solo iba en contra de la estética de la Corte, sino que además hacía que se mostrara acorde con los principios ilustrados y liberales de corte político e intelectual, lo que hacía que minara la imagen de la Corona, ya que ella seguía la estética anglosajona liberal que se estaba extendiendo por casi toda Europa. ${ }^{5}$ Este es un breve ejemplo de cómo el saber leer la indumentaria y la estética de una época puede mostrar detalles que a simple vista pasan desapercibidos, y que pese a que los primeros escritos sobre moda tratados sobre los estudios de la moda y la estética aparecieran en el siglo XIX con Balzac y su Tratado de la Vida Elegante o Baudelaire con El pintor de la vida moderna la importancia y el significado de la moda a nivel estético y como portadora de un mensaje venía de siglos atrás. Es en el siglo XX ,sin embargo cuando empiezan a proliferar los estudios sobre la moda y su importancia a nivel social e histórico.

La moda moderna no se puede definir en una sola palabra, pero si hubiera que encontrar una definición corta, sería el ansia por la novedad, la obsesión por el avance, el cambio y la independencia. Así la definió Georg Simmel filósofo y sociólogo, aseverando que la moda es hoy sabiendo que mañana no será, y sin embargo a la vez es algo atemporal, ya que no tiene en cierto modo un presente, pues "oscila entre el pasado y el futuro con tanta rapidez que en el momento en que alcanza su apogeo presente, comienza a ser pasado." ${ }^{6}$ Uno de los principios es la variación estética, pero como en todo lo demás hay una clara tendencia a economizar el esfuerzo, por lo que se puede hablar de una ruta circular. Es decir, recae siempre en formas anteriores, pero de una manera que o bien resulta imperceptible o siempre presenta una evidente novedad. La moda que sigue a una moda llama la atención porque es deliberadamente distinta y el contraste es muy evidente, por lo que al ser olvidada, siempre hay un momento futuro en el que los diseños recuperan algún

\footnotetext{
${ }^{4}$ López Lloret, J., 'Jean-Jacques Rousseau y la cultura del diseño", ÁGORA. Papeles de Filosofía, Julio 2014, p.23

5 Cerrillo, L., La moda moderna. Génesis de un arte nuevo, op.cit, p.27

${ }^{6}$ Simmel, G, Filosofía de la Moda (1905), Madrid, Ed. Casimiro, 2014, p.17
} 
rasgo del pasado. ${ }^{7}$ Bajo la expresión Sub especie aeternitatis, que literalmente significa "fugacidad bajo el aspecto de eternidad", Simmel describió y trató de explicar el concepto "moda". Habiendo tomado la expresión de Spinoza, el cual se refería con esta expresión a la existencia misma del hombre, quien vive como si pensara que fuera eterno, él extrapoló este sentido al modo de vestir, el cual tiende a presentarse como si fuera a ser eterno, cuando su principal característica es la volatilidad.

Simmel asevera, por ejemplo, que las clases inferiores siempre tienden a imitar a las superiores, reafirmando así la posición de superioridad de estas últimas, de manera que cuando el vestir de las clases altas se popularizaba entre las más bajas, esta moda era abandonada en pos de otra más novedosa. Según apunta Ana Velasco: ${ }^{8}$

"El deseo de ser lo que no se es, encuentra en la indumentaria una herramienta clave y la moda pasa a ser, con más fuerza que nunca, en un elemento manejado por la burguesía para enriquecerse, y paradójicamente, ennoblecerse. El vestir se convierte, en los albores de 1800 en un factor cultural."

Por otro lado, Jean Baudrillard defendía que la moda jamás pierde su base de abolición del pasado, de manera que se puede entender como un concepto de muerte y resurrección. Aseguraba además, que "si la modernidad es un código, la moda es su emblema", ${ }^{9}$ puesto que nada representa mejor el momento presente y nada es nunca más moderno ella. Esta última idea la rescata de Baudelaire, quien planteó además otro de los principios más abstractos pero más importantes respecto a este tema: "Extraer de la moda lo que ésta puede contener de poético en lo histórico" ${ }^{10}$, buscando transformar los problemas acontecidos en la época en belleza a la vez que pretende plasmar un momento fugaz y transitorio de la historia en una creación física.

Entre los estudios teóricos más recientes y extensos del siglo XX, se encuentra el filósofo Guilles Lipovetsky, quien defiende que el objetivo del cambio estético en la época moderna y de la creación de nuevos diseños indumentarios es romper con el pasado inmediatamente anterior al de la etapa que se está desarrollando. ${ }^{11}$ Se busca olvidar, constantemente también existe una alusión a épocas pasadas consideradas mejores o culturalmente más ricas por algún motivo.

El cambio en la manera de vestir siempre es homogéneo en cualquier época. Se tiene como una regla social no escrita, como si la masa de gente estuviera incons-

\footnotetext{
7 Ibid, p.25

Velasco, A, Moda y prensa femenina en la España del siglo XIX, Madrid, Ediciones 19, 2016, p.51

9 Sheringam, M, "Fashion, theory and the everyday", Dalhouse University: Inspiring minds. Vol, 53, 2000, p.151

${ }^{10}$ Baudelaire, C, El pintor de la vida moderna (1860), Murcia, Colección Arquitectura 30, 2014, p.91

11 Lipovetsky, C, El imperio de lo efimero, op.cit, p.71
} 
cientemente coordinada y tuviera ese objetivo común; pero si bien siempre se ha impuesto una norma en conjunto, a la vez se ha pretendido dejar un sitio al gusto personal de cada persona: ser como los demás, pero no absolutamente como ellos, pues entonces nada nos haría destacar entre el resto. ${ }^{12}$ Un cambio colectivo en el gusto estético no sugiere la pérdida de gusto individual, sino la adaptación común a nuevos tiempos manteniendo el poder sobre el gusto propio: por ejemplo, predominan las líneas rectas en los vestidos y el uso de sombreros, pero está en la mano de cada cual decidir de qué color se viste, cómo los conjunta y de qué forma prefiere su sombrero.

\section{Los cambios más significativos de la moda}

Los DISEŃOS DE LUJO siempre han sido sinónimo de pertenecer a una clase social alta y de tener un gran respaldo económico, por lo que durante siglos, las mejores vestimentas estuvieron solo al alcance de unos pocos, de manera que la gente con menos dinero se hacía la ropa a sí misma, con materiales considerados más pobres, e intentando imitar en muchos casos el estilo de las clases más altas. Sin embargo, muchas veces los propios monarcas del siglo XVII, impedían con sus leyes suntuarias el consumo desenfrenado de telas para emular a las clases sociales más altas como apunta Hugh Trevor-Roper en su libro: "En 1624, Felipe IV redujo su personal, publicó leyes suntuarias y desterró la gorguera, símbolo neto de magnificencia en el vestir de España por decreto, y de Europa por ejemplo" ${ }^{13}$.

Sin embargo, los vaivenes de las tendencias, dieron lugar a que poco a poco surgieran figuras icónicas en las monarquías europeas como fue el caso de la española $M^{a}$ Eugenia de Montijo en Francia, casada con el emperador Napoleón III, o Isabel de Baviera, más conocida como Sissi, que influyeron en pleno romanticismo, en el vestir de las damas de la burguesía o alta nobleza. La divulgación de las primeras revistas ilustradas de Moda, con figurines e ilustraciones ayudaron a ello.

Todo esto cambió radicalmente en las primeras décadas del siglo XX debido a la denominada "democratización de la moda", que provocó que los diseños se simplificaran poco a poco, los materiales estuvieran al alcance de todo el mundo, y el estilo en general dejara de reflejar una complejidad solo al alcance de unos pocos; de manera que al ser más sencillos, la separación de clases visualmente se hizo menos evidente.

\footnotetext{
12 Simmel, G., (1908). "El problema del estilo". Revista REIS No. 84. Octubre-Diciembre 1994. Monográfico sobre sociología del arte, p.321

${ }_{13}$ Trevor-Roper, H, La crisis del siglo XVII: Religión, Reforma, y cambio social, Madrid, Liberty Fund y Katz ed, 2009, p.83
} 
También influyó en esto, la aparición de las diseñadoras, quienes con sus diseños más sencillos y cómodos, como más adelante se verá, aseguraron que un hombre no conocía el cuerpo de una mujer ni las necesidades de ésta como la propia mujer, por lo que eran ellas quienes debían diseñar la ropa femenina. A eso se le sumó la situación política y económica, así como los movimientos sociales por la igualdad entre personas y entre géneros, lo cual tuvo también su repercusión en el modo de vestir.

Lo anteriormente expuesto definió el camino hacia la moda actual, que poco a poco fue perdiendo el concepto de lujo absoluto como separador de clases sociales debido a la paulatina aparición de la democratización de la moda: la Alta Costura y el lujo siguieron presentes, pero la indumentaria cada vez estaba más encaminada hacia la globalización, de manera que la producción en cadena de nuevos diseños abarataba costes y permitía que prácticamente todo el mundo tuviera a su alcance los nuevos estilos, lo que como más adelante se verá redefinió el concepto de moda y su entendimiento. Es todo esto lo que se puede apreciar con la evolución de los diseños y el nacimiento de las nuevas modas.

Por tanto, una vez que se consolida en el siglo XX el concepto de la importancia de la moda se alcanza por completo la democratización, y el momento en el que el significado cambió totalmente, además de comenzar a haber cambios extraordinariamente rápidos. Es muy importante además tener en cuenta que el foco se pone sobre la silueta femenina, que siempre ha sido el objetivo fundamental de la moda y los diseńadores. La estética del siglo XX refleja la gran cantidad de cambios acontecidos en él. Si bien la primera década, más tranquila a nivel político y social en Europa, heredó del XIX el tomar el cuerpo de la mujer como un lienzo para adaptarlo, mediante la manera de vestir y las formas de los vestidos, a los ideales estéticos del momento, fue a partir de 1910 cuando la forma de vestir no paró de cambiar, siguiendo una única regla: cuanto más convulso el momento, más bruscos los cambios estéticos.

Grandes nombres de diseñadores comenzaron a surgir, nombres que firmaban sus creaciones y las hacían no solo globales, sino dignas de imitación, y cuyo trabajo sirve para ilustrar todas las ideas planteadas anteriormente. Uno de los primeros diseñadores que fundió su propia visión de la moda con la sociedad del momento y la influencia artística fue Paul Poiret, que introdujo la moda en el mundo del arte y provocó un cambio en el canon de belleza femenino y la idea de la mujer, de manera que estableció una conexión directa con los artistas plásticos y las corrientes del momento. ${ }^{14}$ En sus diseños de la primera década del siglo XX se plasma todavía el

${ }_{14}$ Riello, G., Breve historia del traje y la moda. Desde la Edad Media hasta la actualidad, Barcelona, Ed. Gustavo Gili, 2016, p.108 
conocido exotismo de la segunda mitad del siglo XIX, donde la sociedad occidental estaba fascinada por todo aquello que desconocía y que por lo tanto era tachado como exótico. Los vestidos reflejaban la fascinación por las sedas orientales, la recuperación de las formas clásicas de la Antigüedad. Esa herencia de los largos viajes para conocer mundo quedaba reflejada en la forma de vestir, dejando ver además algo más: el concepto de belleza siguió unido al de riqueza. ${ }^{15}$

Fue Poiret quien eliminó de manera definitiva uno de los pilares fundamentales de la vestimenta femenina desde el siglo XV: el corsé. Esta decisión significó además enfrentarse a un reto complicado: resolver la sustitución no solo del canon de belleza implantado por el corsé, sino ser capaz de superarlo para que tuviera una aceptación completa por parte de la sociedad. Así, encontró su inspiración en la estética griega, ya que advirtió que era posible crear un vestido teniendo como único punto de apoyo los hombros en lugar de la cintura ${ }^{16}$. Los diseńos, pese a no dejar de lado en ningún momento la búsqueda de la elegancia y la belleza, comenzaron a tener una gran sencillez, por lo que a partir de 1900 toda la moda femenina perdió mucho volumen y ganó comodidad y libertad de movimientos. ${ }^{17}$

Poiret se definía a sí mismo como un artista y la sociedad lo aceptó como tal. Fue entonces cuando conoció a Man Ray y comenzaron a trabajar juntos. Desde sus primeras sesiones fotográficas, registradas en 1921, ManRay dispuso de total libertad para utilizar la casa de Poiret para sus escenografías. El fotógrafo descubrió la gran colección de arte que poseía el diseñador y decidió usar muchas de las obras para sus fotografías, siendo consciente de que así les daba aplomo y un signo de distinción, como el pájaro de Brancusi, ${ }^{18}$ lo cual provocó que los diseños de Poiret y las fotografías en sí tuvieran una carga cultural evidente.

Ya en los años 20, tras finalizar la Primera Guerra Mundial surgió en Estados Unidos un nuevo estilo que luego se extendió hasta el Viejo Continente: la música jazz. Este estilo musical, sumado a la situación social de furor por el fin de la guerra, influyó en el cambio de los vestidos en los años veinte: se acortaron por las rodillas, y se ajustaron por debajo de la cadera para permitir más movilidad. La mayoría de mujeres jóvenes se cortaron el pelo al estilo Bob Cut, salieron a bailar en grupo por las noches sin acompañantes masculinos, comenzaron a fumar y beber en público sin ningún recato; fueron las denominadas flappers, 19que fueron las primeras en

\footnotetext{
15 Yapp, N., 1900's. Decades of the 20th century, Getty images, Ed.Konneman, 2004, p.122

${ }^{16}$ Laver, J., Breve historia del traje y la moda, Madrid, Cátedra, 1988, p.151

17 Yapp, N., 1900's. Decades of the 20th century, op.cit, p.123

${ }_{18}$ Cerrillo, L., La moda moderna. Génesis de un arte nuevo, op.cit, p.89

19 El término flappers proviene de la palabra flapping, que era el aleteo de brazos que se hacía al bailar la música del momento, así como a la película The Flapper (1920), que fue la primera en retratar el estilo de vida y el modo de vestir de las mujeres en esta época.
} 
rechazar abiertamente cualquier tipo de comportamiento establecido como "moralmente aceptable" para una mujer, y todos estos cambios estéticos fueron el reflejo de una idea: que durante los años de la guerra, fueron las mujeres quienes tuvieron un gran peso a la hora de sacar adelante los países y sus familias, pudiendo ser independientes.

En la segunda década del siglo XX aparece una figura fundamental: Coco Chanel, siendo sus años dorados los años treinta y cuarenta. La diseñadora Gabrielle "Coco" Chanel reinventó la moda femenina. Mientras Poiret estuvo en cercana relación con el grupo fauvista, Chanel lo estuvo con los cubistas, de manera que su figura y su estilo se perfilaron con total nitidez a la hora de conjugar creatividad y practicidad. La amistad que tuvo con los grandes representantes de la vanguardia le sirvieron de inspiración para reorientar las relaciones entre la moda, la sociedad y el arte. Unió la racionalidad y practicidad de la Bauhaus y las ideas y estética de los artistas cubistas, para poder unir los dos pilares fundamentales sobre los cuales se sustentan sus creaciones: elegancia y comodidad. ${ }^{20} \mathrm{Su}$ ropa siempre se mostró como algo fácil de entender y de vestir, y por lo tanto de popularizar; uniendo la maestría de la Alta Costura, pues todos sus diseños estaban hechos a mano, con la cultura popular, sus diseńos tenían líneas rectas y estaban hechos con materiales hasta entonces considerados "poco nobles", como lana y algodón. ${ }^{21}$ Creó trajes de tweed para las mujeres, jerséis, pantalones, ropa de sport y zapatos planos, sin dejar de lado los vestidos de gala, todo abanderado por la comodidad y la elegancia. Ella misma aseguró que suprimió el corsé y todo aquello que coartara la movilidad y comodidad porque cualquier elemento que subyugara físicamente a la mujer a la hora de vestir la conducía a una inconsciente subyugación psicológica. ${ }^{22}$ De esta manera sus creaciones se adaptaban a la realidad, resultando un fiel reflejo del tiempo presente, creadas con lógica y atendiendo a las necesidades.

A nivel internacional estos últimos ejemplos expuestos sirven para ilustrar y ejemplificar no solo la unión de la moda con todo lo que le rodea, así como por qué cambia la estética de un momento, sino también como a nivel identitario la sociedad viste de cierta manera porque se ve no solo identificada con esa corriente estética, sino porque esta es un reflejo de todo lo que está aconteciendo y de la mentalidad de la época.

En la década de 1940 sin embargo, España no seguía la misma estética que el resto de Europa. Tras la Guerra Civil y la victoria del bando nacional, se instauró la dictadura franquista. Entre 1930 y 1960 el país estuvo sumido en lo que se conoce

\footnotetext{
${ }^{20}$ Charles-Roux, E., Descubriendo a Coco, Barcelona, Penguin Random House , 2015, p.107

${ }^{21}$ Cerrillo, L., La moda moderna. Génesis de un arte nuevo, op.cit, p.119

22 Lipovetsky, C., El imperio de lo efimero, op.cit, p.116
} 
como la época de autarquía española, agravada en una profunda crisis económica debido a la guerra acontecida. Esto tuvo una repercusión directa en el estilo de vida de los españoles, acentuadas las dificultades internas por el aislamiento de España a nivel internacional, ya que en vistas de la Segunda Guerra Mundial, el resto de países negaron las relaciones con Espańa debido al nuevo régimen dictatorial instaurado. ${ }^{23}$ Se volvió a un arte tradicional, que ensalzaban a los grandes maestros del barroco español. Los movimientos que defendían o proclamaban el arte vanguardista desaparecieron para que el sistema artístico se readaptara y proclamara la tradición, la españolidad y se ciñera al catolicismo, ya que éste debía estar presente en cualquier manifestación cultural o científica. ${ }^{24} \mathrm{Tal}$ atmósfera también actuó de condicionante al desarrollo de otra rama que apenas goza de atención: la moda y la estética.

Atrás quedaron los vestidos de los años 20 llenos de brillos y flecos, el maquillaje llamativo y los cortes de pelo a lo garçon. La moda en España, se refiere a aquella que se vinculaba a la mujer en las altas esferas, recuperando la idea de que solo aquellas mujeres de clase alta podían vestir de manera completamente apropiada y acceder a los mejores diseñadores, volviendo así a la separación de clases. Es curioso así, que en una época en la que la industria apenas tuvo desarrollo y se volvió a unas raíces agrarias, la industria que más prosperó durante la autarquía fue la industria de la moda con la creación de la Cooperativa de Alta Costura en 1940 conformada por Los cinco grandes: Pedro Rodríguez, El Dique Flotante, Asunción Bastida, Manuel Pertegaz y Santa Eulalia.

Por tanto, se podría decir que si bien el panorama de la estética y la moda a principios del siglo XX ha sido muy estudiado y es muy conocido, no es así con la moda española de la misma época. Los estudios sobre ella son escasos y si bien sí se conoce la existencia de la Cooperativa de Alta Costura y los diseñadores que la formaron, es desconocida la incidencia que tuvo en el ámbito político a nivel nacional e internacional. Así, es importante tener en cuenta que los contactos oficiales a nivel comercial entre Espańa y EE.UU comenzaron en 1953 con los Pactos de Madrid. Sin embargo ya hubo contacto comercial antes gracias a la industria de la moda, siendo este hecho verificable gracias a la documentación extraída en la prensa de la época. Prueba de ello, fue la inauguración en 1952 del I Festival de Moda Internacional en Madrid y al que acudieron grandes personalidades de todos estos países. ${ }^{25}$

\footnotetext{
${ }^{23}$ Bernecker, W.L. España: entre tradición y modernidad. Politica, economia, sociedad (siglos XIX Y XX), Madrid, Siglo XXI editores, 2009, p.288

${ }^{24}$ Díaz Sánchez, J. Llorente Hernández, A. La crítica de arte en España (1939-1976), Madrid, Ediciones Itsmo, 2004, p.11

25 Archivo Museo del Traje, CIPE, Álbum Recortes de prensa nacional 1952, doc.SEQ-012-R
} 
El arte español con frecuencia se unía a la exaltación de la españolidad, y esto se extrapoló a las creaciones de cada diseñador, que estaban inspiradas en artistas como Goya o Zurbarán ${ }^{26}$ pero se hizo de tal manera que los diseńos coexistieron con el tradicionalismo defendido por el régimen franquista y con la modernidad europea, además de jugar con la elegancia y la figura femenina a la vez que con la sobriedad, por lo que su impacto fue enorme. Esto deja ver dos caras de la moneda: la lectura que hacían los extranjeros de sus diseños, como si fueran una oda a la cultura española y su historia, y el porqué sus creaciones eran así: porque seguían la doctrina de la ideología nacional. Jugar con el tradicionalismo español y la modernidad de Europa jugaba a favor de Espańa, ya que los diseños de Alta Costura tenían un porqué y un mensaje detrás, además de grandes calidades capaces de competir con París, pero a menores precios debido a la crisis económica, lo que provocó que el país adquiriera gran importancia a ojos de otros países.

El gobierno español encontró en la moda un salvoconducto para entrar en el mercado internacional comerciando con los diseños de Alta Costura, captando inversores y clientes, de manera que se estableció contacto con ellos de manera distendida y no oficial. Mientras, a nivel nacional, cada temporada se celebraban los Salones de la Moda en el Ritz de Barcelona, los cuales comenzaron a celebrarse en 1944, siete años antes que el Salón de la Moda Internacional, lo cual muestra el temprano contacto que España logró establecer con la moda a nivel internacional. ${ }^{27}$

El interés de Estados Unidos por la moda espańola fue tal, que si bien en 1953 el gobierno español se comprometió de manera oficial a estabilizar la moneda o bajar los arancel es para facilitar el comercio, en 1952 se hizo un algo parecido para que el comercio textil con EE.UU fuera posible, tal como se puede leer en un artículo escrito por Jane Cianfarra para The New York Times ${ }^{28}$ : Se facilitó el cambio de divisas y se llegó a un acuerdo en el valor de la moneda satisfactorio para ambos países, para no poner impedimento a la hora de hacer los trámites y expedir visados para que tanto los diseñadores y sus ayudantes, como los comerciantes, pudieran salir del país sin problema. En el mismo año, The Daily Telegraph proclamó a los diseñadores de la Cooperativa de Alta Costura como "embajadores" de Espańa, pues si bien no tenían nada que ver de manera directa con la política, sí transmitían un mensaje social y actuaban como nexo de unión entre ambos países. ${ }^{29}$

\footnotetext{
${ }_{26}$ Sousa Congosto, F, Introducción a la historia de la indumentaria española, Madrid, Ed. Itsmo, 2007, p.230

27 Ajuntament de Barcelona: Barcelona en posguerrahttp://www.bcn.cat/bcnpostguerra/exposiciovirtual/ es/3.4-salon-de-la-moda-espanola.html

${ }_{28}$ Archivo Museo del Traje, CIPE,Álbum Recorte prensa extranjera 1952, doc. SEQ-017-Q

29 Archivo Museo del Traje, CIPE, Álbum Recorte prensa extranjera 1952, doc. SEQ-018-R
} 
En la prensa nacional del momento se encuentran otros ejemplos, como el localizado en el diario "El Pueblo de Madrid" donde la esposa del embajador espańol negaba en una entrevista en News Chronicle que la moda en España inspirada en el folclore y los artistas barrocos más importantes, estuviera ligada al "supuesto" conservadurismo extremo, siendo ésta una simple oda a la historia del país. ${ }^{30}$ Este es un ejemplo de cómo la identidad e imagen de un país podía ser entendida de diversas maneras dependiendo de cómo el mensaje se leyera, siendo el mensaje transmitido en este caso por la estética y la forma de vestir. No era la intención de las clases altas y de la prensa dar una impresión de ostracismo, sino una imagen de cultura y diseño basada en el pasado del país como si de una oda se tratara.

Sirvan estas breves pinceladas de cómo la moda en España sirvió no solo de imaginario para plasmar la situación del país en ese momento, siendo fiel ejemplo de la sociedad y cómo esta estaba organizada, sino como instrumento para tejer relaciones internacionales y para que el gobierno y la prensa exaltaran al país, cumpliendo así la máxima de que la moda no es solo moda, y que la estética plasma mucho más que el gusto, siendo el símbolo de una identidad. Tras los ańos de auge de la Alta Costura en España, ésta comenzó a decaer en cuanto España abrió sus puertas al turismo y el contacto con el resto del mundo que se hizo más patente en los años sesenta por una incipiente apertura de la dictadura hacia el exterior.

Europa y Estados Unidos se sumieron en un frenesí de globalización: en una época en la que las imágenes comenzaron a llenar las revistas, periódicos y pantallas de televisión, todo empezó a producirse en masa y cada vez más rápido y con mejor calidad, lo que repercutió directamente en la moda, que entró en una etapa conocida desde entonces como democratización: ropa barata al alcance de todo el mundo, no hecha a medida ni a mano, sino en cadena, lo que provocó un cambio radical en el concepto; la manera de vestir no solo se universalizó y se creó un estilo único a nivel internacional, sino que se eliminó totalmente la separación visual entre clases sociales.

Estos cambios provocaron la pérdida de la esencia, de un mensaje creador, y por lo tanto de la pérdida de interés por un estudio teórico individual, sino que la moda se asoció a la cultura de masas y actualmente es un reflejo fiel de la cultura de la modernidad, ${ }^{31}$ concepto que refleja Giorgio Riello en su libro ${ }^{32}$ :

"La globalización del mercado de consumo y del trabajo, convierten en obsoletas las denominaciones nacionales que tanto han influido en el sistema de la moda del pasado"

\footnotetext{
30 Archivo Museo del Traje, Cipe, Álbum Recorte de prensa nacional 1952, doc. SEQ-021-R

31 VV.AA, Los gustos y la moda a lo largo de la historia, Ediciones Universidad de Valladolid, Valladolid, 2014, p.234

32 Riello, G, Breve historia de la Moda. Desde la Edad Media hasta la actualidad, op.cit, p.162
} 
Si algo define a la cultura de masas es el consumismo: se busca consumir en arte, en cine, en literatura, en moda, en viajes. Se busca la novedad por encima de todo en un momento en que la curiosidad, una de las características principales del ser humano, nunca se sacia ${ }^{33}$ porque el consumo lo ha absorbido todo. Al encontrarse todo al alcance de cualquiera, nada es nunca suficiente y la exigencia general es cada vez más alta, lo cual deriva en una reflexión: la pérdida completa de, como se mencionó anteriormente, el concepto de sublimidad, de lo inalcanzable. El deseo ha perdido su concepción como idea y se ha materializado a causa del mercado, que anula la distancia entre objeto y sujeto, matando así cualquier posibilidad de reflexión sobre lo inalcanzable o, este caso, lo conseguido. ${ }^{34}$ Una vez que se tiene, se pierde el interés y se busca otra cosa.

Este cambio, de nuevo, se refleja en pleno siglo XXI, en la manera de vestir, donde ahora prima la cultura de fast fashion donde se toman ideas de las pasarelas para realizar diseños a bajo coste. Cada temporada es necesario cambiar, renovarse, porque la vergüenza ya no está en no vestir con las mejores firmas y calidades, sino en estar pasado de moda, en quedarse estancado y no poder seguirle el ritmo a la sociedad y sus avances. Incluso las firmas en las que aun permanece la Alta Costura presentan varias colecciones al año para saciar el deseo y exigencia de los consumidores.

Para concluir este análisis volvemos a Baudelaire hablando de lo bello, y sus interrelaciones en el tiempo con elementos circunstanciales como es el vestir en las diferentes épocas:

"Lo bello es siempre, inevitablemente, de una doble composición, aunque la impresión que produce sea una: pues la dificultad del discernir los elementos variables de lo bello en la unidad de la impresión, no invalida en nada la necesidad de la variedad en su composición. Lo bello está hecho de un elemento eterno, invariable, cuya cantidad es difícil de determinar, y de un elemento relativo, circunstancial, que será, si se quiere, por alternativa o simultáneamente, la época, la moda, la moral, la pasión”. ${ }^{35}$

\footnotetext{
33 Bozal, V, Necesidad de la Ironía, Madrid, Editorial Antonio Machado, 1999, p.12

${ }^{34}$ Ibid, p. 17

35 Baudelaire, C, Salones y otros escritos de arte, Madrid, Editorial Antonio Machado, 2005, p-350-351
} 


\section{ReFERENCIAS Bibliográficas}

Balzac, Honoré, Tratado de la vida elegante, Madrid, Impedimenta, 2011

Baudelaire, Charles, Salones y otros escritos de arte, Madrid, Editorial Antonio Machado, 2005

Baudelaire, Charles, El pintor de la vida moderna, Murcia, 1995, Colección de Arquitectura 30, 2014

Bernecker, W.L. España: entre tradición y modernidad. Politica, economía, sociedad (siglos XIX Y XX), Madrid, Siglo XXI editores, 2009

Bozal, Valeriano, Necesidad de la Ironía, Madrid, Editorial Antonio Machado, 1999

Cerrillo Rubio, Lourdes, La moda moderna. Génesis de un arte nuevo, Madrid, Ed. Siruela, 2010

Charles-Roux, Edmon, Descubriendo a Coco, Barcelona, Penguin Random House Grupo Editorial, 2015

Díaz Sánchez, Julián, Llorente Hernández, Ángel. La crítica de arte en España (1939-1976), Madrid, Ediciones Itsmo, 2004

Laver, James, Breve Historia del traje y la moda, Madrid, Cátedra, 1988

Lipovetsky, Charles, El imperio de lo efimero, Barcelona, Anagrama, 1996

Riello, Giorgio, Breve historia del traje y la moda. Desde la Edad Media hasta la actualidad, Barcelona, Ed. Gustavo Gili, 2016

Simmel, Georg, Filosofía de la Moda, Madrid 2014, Ed. Casimiro

Simmel, Georg (1908). El problema del estilo. Revista REIS No. 84. Octubre-Diciembre 1994. Monográfico sobre sociología del arte

Sheringam, Michael, "Fashion, theory and the everyday", Dalhouse University: Inspiring minds. Vol, 53, 2000

Sousa Congosto, Francisco, Introducción a la historia de la indumentaria española, Madrid, Itsmo, 2007

Trevor-Roper, Hugh, La crisis del siglo XVII: Religión, Reforma, y cambio social, Madrid, Liberty Fund y Katz ed, 2009

VV.AA, Los gustos y la moda a lo largo de la historia, Ediciones Universidad de Valladolid, Valladolid, 2014 
Velasco, Ana, Moda y prensa femenina en la España del siglo XIX, Madrid, Ediciones 19, 2016

Yapp, Nicky, 1920's. Decades of the 20th century. Gettyimages, 2004

\section{Webgrafía}

Ajuntament de Barcelona: Barcelona en posguerra http://www.bcn.cat/bcnpostguerra/exposiciovirtual/es/3.4-salon-de-la-moda-espanola.html

DOI: https://doi.org/10.15366/bp.2020.24.021

Bajo Palabra. II Época. No 24. Pgs: 415-430 